\title{
KONTRIBUSI PESANTREN DALAM MERESPON DINAMIKA SOSIAL KEAGAMAAN
}

\author{
Muhaemin \\ Institut Agama Islam Negeri Palopo \\ Jl. Agatis Balandai Kota Palopo 91914 Sulawesi Selatan, Indonesia \\ E-mail: muhaemin@iainpalopo.ac.id
}

\begin{abstract}
This study aims to analyze and map the role of pesantren in social aspects and religious development in its relevance to local culture and global dynamics. The study design used a qualitative approach with a number of selected informants. The research location was in the Nurul Junaidiyah Lauwo Luwu Timur Islamic boarding school which was one of the pesantren that developed in the Tana Luwu area of South Sulawesi. The results of the study showed that the Islamic Boarding School Nurul Junaidiyah had carried out a role in the social field, namely holding formal education, accommodating santri from poor families, organizing economic empowerment activities through cooperatives. In the aspect of religious development, the Pesantren Junaidiyah Lauwo became a pioneer of moderate Islamic da'wah involving Kyai, Caregivers, Teachers, santri and alumni. Along with the global dynamics, it is necessary to increase the role of pesantren through cooperation with alumni ties, government, and other institutions. In the aspect of religious development, the Nurul Junaidiyah Islamic Boarding School has made good contributions, especially in printing the memorization of the Koran, but the social aspects need to improve social programs such as fostering orphans, fostering converts and or establishing ulema cadre centers (ma'had aly).
\end{abstract}

Keywords: The role of Pesantren, social, religious development, PNJ Lauwo Burau.

\begin{abstract}
Abstrak
Penelitian ini bertujuan untuk menganalisis dan memetakan peran pesantren dalam aspek sosial dan pembangunan keagamaan relevansinya dengan budaya lokal dan dinamika global. Desain penelitian menggunakan pendekatan kualitatif dengan sejumlah informan terpilih. Lokasi penelitian di Pesantren Nurul Junaidiyah Lauwo Luwu Timur yang merupakan salahsatu pesantren yang berkembangan di kawasan Tana Luwu Sulawesi Selatan. Hasil Penelitian menunjukkan bahwa Pesantren Nurul Junaidiyah telah melaksanakan peran di bidang sosial yaitu menyelenggarakan pendidikan Formal, menampung santri dari keluarga miskin, menyelenggarakan kegiatan pemberdayaan ekonomi melalui koperasi. Dalam aspek pembangunan keagamaan, Pesantren Junaidiyah Lauwo menjadi pelopor dakwah Islam moderat dengan melibatkan Kyai, Pengasuh, Guru, santri dan alumni. Seiring dengan dinamika global, perlu peningkatan peran pesantren melalui melakukan kerja sama dengan ikatan alumni, pemerintah maupun lembaga lainnya. Dalam aspek pembangunan keagamaan, Pesantren Nurul Junaidiyah telah memberikan kontribusi yang baik khususnya mencetak penghafal al-Qur'an, namun aspek sosial perlu meningkatkan program-program sosial seperti pembinaan anak yatim, pembinaan muallaf dan atau mendirikan pusat kader ulama (ma'had aly).
\end{abstract}

Kata Kunci,: Peran Pesantren, Dinamika sosial, pembangunan keagamaan, PNJ Lauwo Burau. 


\section{2 | Muhaemin}

\section{PENDAHULUAN}

Pendidikan Islam dengan berbagai bentuknya perlu melakukan penyesuaian dengan era sekarang ini yang merupakan era disruptip. Pesantren sebagai bagian dari Pendidikan Islam dituntut melakukan berbagai upaya merespoen industri. 4.0. Pesantren perlu menjalin kerjasama dengan berbaik pihak. Pesantren juga perlu melakukan inovasi dalam metode pembelajaran, dan pengabdian. Selain itu santri dituntut untuk mendapatkan pembelajaran yang tidak hanya tektual tetapi juga pendekatan kontekstual. ${ }^{1}$

Pembahasan tentang dinamika pendidikan di Indonesia adalah hal menarik. Indonesia memiliki lembaga pendidikan yang beragam dalam kondisi sosial masyarakat yang memiliki keragaman budaya, bahasa, dan tradisi keagamaan. Di sisi lain, masyarakat Indonesia sangat menghargai kedudukan tokoh pendidik dan tokoh agama. Kegiatan pendidikan formal, informal dan non formal berjalan dengan seiring sejalan. Dengan kondisi seperti di atas, maka peran lembaga pendidikan di Indonesia dalam dinamika sosial keagamaan sangat signifikan.

Masyarakat Indonesia yang berada di pedesaan sebagian besar belum menempuh pendidikan tinggi. Dalam sepuluh tahun terakhir, angka sarjana terus meningkatkan, namun penduduk (kalangan orang tua) di tinggal Pedesaan hanya menyelesaikan pendidikannya pada SD, SMP dan SMA saja. Masyarakat yang memiliki ilmu agama yang memadai juga sangat sedikit, karena sebagian besar waktu mereka digunakan untuk bekerja di sawah, di kebun atau di laut. Dalam situasi masyarakat seperti ini, kehadiran lembaga pendidikan yang memiliki fungsi dakwah dan fungsi sosial sangat dibutuhkan.

Pondok pesantren adalah salahsatu lembaga pendidikan yang banyak memberikan kontribusi dalam dinamika sosial keagamaan di Indonesia. Secara sosial, pondok pesantren memberikan layanan pendidikan mulai dari pendidikan anak usia dini hingga perguruan tinggi. Secara keagamaan, pondok pesantren adalah pusatreproduksiulama. Pengasuh, alumni dan peserta didik di pondok pesantren adalah satu kesatuan yang secara terus menerus bekerja untuk mencerdaskan calon pemimpin bangsa.

Lembaga pendidikan seperti pondok pesantren dituntut memberikan peran secara sosial dan juga keagamaan. Masyarakat membutuhkan bantuan non fisik yang dapat memberikan pencerahan dan bimbingan dalam peningkatan pengetahuan keagamaan dan juga sosial ekonomi. Di sisi lain, masyarakat juga sering dihadap pada berbagai masalah kekeluargaan seperti pembagian harta warisan. Dalam kondisi seperti itu, kehadiran pesantren dapat memberikan kontribusi yang signifikan.

${ }^{1}$ Sigit Priatmoko, "Memperkuat Eksistensi Pendidikan Islam Di Era 4.0," TA"LIM : Jurnal Studi Pendidikan Islam 1, no. 2 (2018): 1-19. 
Di kawasan Tana Luwu Sulawesi Selatan terdapat sejumlah Pondok Pesantren. Pesantren yang cukup tua dan berkembang adalah Pesantren Datok Sulaiman di Kota Palopo, Pesantren Babus Saadah di Bajo Kabupaten Luwu, Pesantren al-Falah di Bone-Bone Kabupaten Luwu Utara dan Pesantren Nurul Junaidiyah di Luwu Utara. Penelitian ini memfokuskan kajian pada peran Pesantren Nurul Junaidiyah di bidang sosial dan dakwah. Pesantren ini dipilih karena merupakan pesantren yang cukup berkembang dan memiliki sejumlah karakteristik yang berbeda dari pesantren lainnya di kawasan Luwu Raya.

Penelitian ini adalah penelitian kualitatif dengan pendekatan studi kasus. Sumber data utama adalah hasil wawancara dengan pembina Pesantren Nurul Junaidiyah dan data tambahan dari alumni Pesantren. Peneliti juga melakukan observasi ke lokasi dan mengamati dari dekat aktifitas di lingkungan pesantren. Untuk memperkuat analisis data, peneliti membaca sejumlah hasil penelitian terkait dengan masalah penelitian. Data yang terkumpul dikategorisasi, dilakukan koding, dianalisis dan penarikan kesimpulan.

Pesantren Nurul Junaidiyah adalah salahsatu pesantren dalam jaringan pesantren di Sulawesi Selatan. Pendiri pesantren ini Dr. (HC) Kyai Haji Abdul Aziz Rajmal, M. HI pernah belajar pada Pesantren As'adiyah Sengkang di Wajo. ${ }^{2}$ Sebelum mendirikan Pesantren di Lauwo, Kyai Aziz pernah menjadi pengasuh pada pesantren Ma'had Hadits Biru di Kabupaten Bone Sulawesi Selatan.

Nursaidah Said (Alumni dan sekarang pendidik di PNJ Lauwo) menjelaskan bahwa Pesantren Nurul Djunaidiyah dulu berawal dari pendidikan diniyah dengan menumpang pada sekolah Negeri yang ada di Burau. ${ }^{3}$ Saat ini pesantren Nurul Junaidiyah Lauwo Luwu Timur membina Taman Kanak-Kanak Islam, Madrasah Ibtidaiyyah, Madrasah Tsanawiyah, Madrasah Aliyah, Sekolah Menengah Pertama dan Kelas Khusus Penghafal alQuran ( tahfidz al-Qur'an). ${ }^{4}$ Pesantren ini terletak di perbatasan Luwu Utara dan Luwu Timur. Pesantren ini cukup berkembang khususnya dengan peserta takhassus tahfidz al-Qur'an. Salah seorang alumni tahfidh dari PNJ Lauwo yaitu H. Sadli Mustafa telah menjadi Aparatur Sipil Negara dengan jabatan peneliti di Balitbang Kementerian Agama di Makassar.

2 D I Sulawesi Selatan, "Dinamika jaringan intelektual pesantren di sulawesi selatan," n.d., 167-81.Jurnal Lentera Pendidikan, Vol. 11 Nomor 2 tahun 2008. http://journal.uinlauddin.ac.id/index.php/lentera_pendidikan/article/view/3774

${ }^{3}$ Nursaidah Said, Wawancara, 3 Februari 2018 di Lauwo

${ }^{4}$ http://referensi.data.kemdikbud.go.id/tabs.php?npsn=40320508 


\section{4 | Muhaemin}

Pesantren Lauwo memiliki peran layaknya panti asuhan yaitu menampung anak yatim untuk belajar di pesantren. Kyai memegang figur sentral dan sangat kharismatik. Manajemen pengelolaan sangat tradisional biaya pengelolaan mengandalkan hasil usaha yang dikelola oleh Kyai. Pendapat ini dikemukakan salah seorang alumni yang juga warga di sekitar Pesantren. ${ }^{5}$

Secara kelembagan, PNJ Lauwo telah menjadi pesantren yang memiliki kelengkapan yang lengkap yaitu Kyai, Mesjid, pembelajaran kitab dan pemberdayaan. Tidak semua pesantren memenuhi hal ini. Seperti penelitian Rosdiana terhadap kapasitas pesantren-pesantren yang ada di Kabupaten Maros, menemukan bahwa tidak semua pesantren memiliki lima komponen pesantren secara lengkap dan berkelanjutan. ${ }^{6}$ Penelitian rahayani dan Yayan tahun 2017 menunjukkan bahwa pesantren memiliki potensi untuk mengembangkan diri dalam merespon tantangan internal dan eksternal. Walaupun sebagian pesantren masih belum mampu mengembangkan seluruh potensinya karena faktor kepemimpinan, partisipasi guru dan pola komunikasi yang berjalan.7

Perkembangan PNJ Lauwo dalam beberapa tahun terakhir cukup signifikan meskipun masih ada santri yang terpaksa tinggal di luar area pondok karena minimnya daya tampung asrama. Keunggulan PNJ Lauwo adalah pada pembinaan tahfizh yang cukup berkembang dibandingkan dengan beberapa pesantren yang ada di kawasan Tana Luwu Sulawesi Selatan.

\section{METODE}

Dalam pemaparan penelitian ini, menggunakan metode penelitian deskriptif eksploratif dengan pendekatan kulitatif (qualitative research). Metode penelitian deskritif eksploratif sebagai riset yang umumnya digunakan untuk mendeskripsikan suatu fenomena atau objek yang ada. ${ }^{8}$ Penelitian ini dilakukan di Pesantren Nurul Junaidiayah, Kabupaten Luwu

5 Abbas Langaji, Alumni PNJ Lauwo ,Wawancara 13 Mei 2018 di Palopo.

6 Ros Diana, "Pemetaan Kapasitas Pesantren Di Kabupaten Maros Provinsi Sulawesi Selatan," Al-Qalam 22, no. 1 (2018): 39, https://doi.org/10.31969/alq.v22i1.295.

7 Rahayani dan Yayan, "RESTRUCTURING AND REDESIGNING THE PESANTREN TOWARD AN EFFECTIVE EDUCATIONAL INSTITUTION," TARBIYA: Journal of Education in Muslim Society 4, no. 2 (2017), https://doi.org/10.15408/TJEM S.V4I2.8009.

8 S Arikunto, Prosedur Penelitian: Suatu Pendekatan Praktek (Jakarta: PT. Rineka Cipta, 1998). 
Timur Sulawesi Selatan. Penelitian ini melibatkan sejumlah subyek penelitian/informan, yaitu:

Tabel 1. Informasi Subjek Penelitian

\begin{tabular}{|l|l|c|c|l|}
\hline No & $\begin{array}{c}\text { Kode } \\
\text { Informan }\end{array}$ & $\begin{array}{c}\text { Usia } \\
\text { (Tahun) }\end{array}$ & $\begin{array}{c}\text { Jenis } \\
\text { kelamin } \\
(\mathrm{L} / \mathrm{P})\end{array}$ & $\begin{array}{c}\text { Gelar Akademik/Jenjang } \\
\text { Pendidikan }\end{array}$ \\
\hline 1 & P1/AAR & 65 & $\mathrm{~L}$ & Drs. M. HI /S2-DR (HC) \\
\hline 2 & P2/HLM & 45 & $\mathrm{P}$ & S. Pd. I/S1-sementara S2 \\
\hline 3 & P3/NS & 45 & $\mathrm{P}$ & S. Ag/ S1-Sementara S2 \\
\hline 4 & P4/NA & 28 & L & Lc, /S1-sementara S2 \\
\hline 5 & P5/ASW & 28 & $\mathrm{~L}$ & S. Pd/S1 \\
\hline 6 & P6/MS & 35 & L & S. Pd/S1 \\
\hline 7 & P7/AB & 46 & $\mathrm{~L}$ & DR/S3 \\
\hline
\end{tabular}

Data dikumpulkan melalui Observasi, Wawancara, serta dokumentasi. Analisis data melalui proses elaborasi dari berbagai sumber, diklasifikasi, diseleksi dan disusun sesuai kategori data yang diperlukan

\section{PERAN SOSIAL PESANTREN}

Pesantren adalah bagian dari lembaga sosial yang mempunyai visi mencerdaskan anak bangsa dengan fokus pada pendidikan keagamaan. Terkait dengan hal tersebut, informan menyampaikan hal-hal sebagai berikut:

“... Pesantren Nurul Junaidiyah didirikan untuk memenuhi kebutuhan masyarakat di Kawasan Luwu Timur dan sekitarnya. Pesantren ini membina sejumlah lembaga pendidikan dan ada program tahfidz alQur'an". (P1)

“...Pesantren Burau menjadi perekat sosial di antara berbagai elemen masyarakat. Hal ini dibuktikan dengan kepercayaan pemerintah dan masyarakat yang menempatkan pimpinan PNJ sebagai ketua MUI Kabupaten Luwu Timur. Luwu Timur adalah kabupaten yang majemuk karena terdapat pemeluk agama Hindu, Katolik, Kristen Protestan". (P2)

Figur Kyai Aziz menjadi salahsatu kunci pelaksanaan peran sosial di Luwu Timur dan sekitarnya. Dengan posisinya sebagai anggota DPRD 


\section{6 | Muhaemin}

kabupaten Luwu dan Ketua MUI Luwu Timur maka Kyai Aziz memiliki akses ke pemerintahan dan legislatif. Selain itu, Kyai Aziz memiliki kepedulian yang tinggi terhadap kebutuhan masyarakat, sehingga perannya tidak dapat dipisahkan dari PNJ Lauwo.

Selain peran figur Kyai yang cukup menonjol meskipun Luwu Timur adalah daerah multikultural. ${ }^{9}$, PNJ Lauwo secara kelembagaan telah melakukan berbagai peran yang variatif sebagaimana disampaikan para informan di bawah ini:

“...PNJ Lauwo memainkan peran sosial yang cukup beragam. Selain menampung peserta didik dalam berbagai jenjang pendidikan, pesantren juga menampung santri dari kalangan tidak mampu. Mengurangi kemerosotan moral (pergaulan bebas.) khususnya di skitar pondok. "(P3)

“... memberikan pengetahuan agama kepada masyarakat. Selain itu, pimpinan dan pengasuh pondok terlibat dalam membantu warga dalam pemecahan masalah sosial sperti warisan." (P4)

“... PNJ melakukan fungsi ganda. Selain menyelenggarakan pendidikan formal, PNJ juga mengirimkan pengasuh dan santi-santrinya untuk melakukan pembinaan keagamaan kepada msyarakat.( P5)

"PNJ telah melahir alumni yang menjadi tokoh masyarakat, tokoh agama dan muballigh. Alumni PNJ menyebar ke berbagai daerah.” (P6)

Peran PNJ Lauwo telah dilakukan dengan berbagai hal. Termasuk adanya koperasi di lingkungan Pesantren. Salahsatu usaha yang cukup berkembang saat ini adalah usaha air kemasan dengan merek Laziz. Air kemasan ini selain memenuhi kebutuhan Pondok juga dijual pada berbagai wilayah di Luwu Timur. Eksistensi usaha di lingkungan pesantren sangat penting, karena selain menjadi media pendidikan bagi santri untuk berwirausaha, juga dapa $\mathrm{t}$ menambah penghasilan pondok.

Kehadiran Ikatan Alumni PNJ Laowu juga membantu pondok dalam melaksanakan peran-peran sosial. Meskipun dalam pengamatan peneliti, kegiatan IKA PNJ Lauwo belum banyak menyentuh pada kegiatan pemberdayaan ekonomi Pondok, sehingga hal perlu menjadi perhatian ke depan. Peran IKA sangat memungkinkan untuk terus ditingkatkan karena beberapa alumini telah menempati posisi strategis seperti Kepala Desa, Polisi, Peneliti, Dosen, Imam Desa, Guru, KUA, Penyuluh, Penghulu dan anggota legislatif.

\footnotetext{
9 BPS Luwu Timur 2018
} 
Menurut pakar sosiologi pendidikan Abdullah Idi, Pendidik harus mengantisipasi globalisasi dengan cara memahami penting menguasai Iptek, mengantisipasi krisis moral, memberikan solusi dari masalah sosial, menjaga identitas bangsa, menyiapkan SDM tangguh untuk berkompetisi secara terbuka. ${ }^{10}$

Muhammad Jamaluddin dalam tulisan yang berjudul "Metamorfosis Pesantren di Era Globalisasi", 2012.11 Hasil analisis Jamaluddin merekomendasikan agar pesantren melakukan revitalisasi kurikulum agar mampu berkiprah di era globalisasi dan menjadi pusat pemberdayaan masyarakat. Revitalisasi dimkasudkan agar pesantren mampu berperan lebih signifikan dalam dinamika sosial masyarakat saat ini.

Optimalisasi peran sosial pesantren dapat pula diawali dengan metode pembelajaran yang variati. Sistem pendidikan di pondok selayaknya menggunakan Tahfidz, hiwar, fath kutub, muqaranah, bahtsul masail, muhadatsah. ${ }^{12}$ Dengan metode pembelajaran yang beragam, maka akan lahir santri yang kretif, mandiri, dan peduli dengan lingkungan.

\section{Peran Pembangunan Keagamaan Pesantren}

Pesantren dibangun oleh masyarakat, melibatkan partisipasi masyarakat dan mendedikasikan dirinya untuk pemberdayaan masyarakat. Untuk mengetahui bagaimana kegiatan keagamaan pesantren Nurul Junaidiyah dapat dilihat dari hasil wawancara berikut ini.

“... PNJ Lauwo memposisikan dirinya sebagai lembaga yang melayani kebutuhan masyarakat, mulai dari urusan kecil hingga urusan besar. Pimpinan pondok berusaha melayani masyarakat untuk kegiatan keagamaan, seperti ceramah agama, khutbah jumat, khutbah idul fiti dan idul adha, memberikan nasihat pernikahan, memberikan tausiyah pada

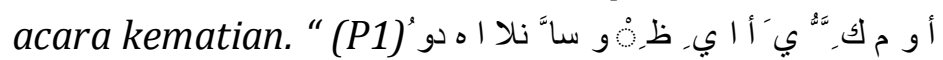

“... pada bulan ramadan, sejumlah santri, pembina dan alumni PNJ Lauwo menjadi imam tarwih di berbagai daerah. Selain itu, PNJ Lauwo juga mengutus

10 Abdullah Idi, Sosiologi Pendidikan Individu, Masyarakat, dan Pendidikan, ed. oleh Safarina HD, Ed. I (Jakarta: Rajawali Press, 2014).

11 Muhammad Jamaluddin, "METAMORFOSIS PESANTREN DI ERA GLOBALISASI," KARSA: Journal of Social and Islamic Culture 20, no. 1 (10 Juli 2012): 127-39, https://doi.org/10.19105/karsa.v20i1.57.

12 B Marjani Alwi, "PONDOK PESANTREN: Ciri Khas, Perkembangan, dan Sistem Pendidikannya," Lentera Pendidikan : Jurnal Ilmu Tarbiyah dan Keguruan 16, no. 2 (2013): 205-19. 


\section{8 | Muhaemin}

Tim dakwah di Kabupaten Soppeng, Sinjai, Pinrang selama 1 bulan. Kegiatan ini diikuti oleh para guru/pembina di PNJ Lauwo." (P2)

“...keberadaan PNJ Lauwo mengurangi bahkan menghilangkn sebagian pemahaman agama masyrakt tentang syirik (mengunjungi muara sungai dengan membuang sesajen dan mengunjungi tempat yang mereka keramatkan. . Pada setiap acara baik walimatul ursy, aqiqah, syukuran, dan lain-lain, masyarakat melibatkan santri untuk pengajian”. (P3)

Peneliti sejarah pendidikan Islam di Indonesia Asrohah menegaskan bahwa sejarah perkembangan kelembagaan pesantren di Indonesia menampilkan empat model besar yaitu pesantren salaf, pesantren dengan sistem pendidikan formal dan berstatus swasta, pesantren yang memiliki Pendidikan dasar hingga universitas dan kampus berbasis pesantren. ${ }^{13}$ Berdasarkan kategori di ats, maka PNJ Lauwo adalah pesantren dengan sistem pendidikan formal dan berstatus swasta dengan kekuatan utama pada kegiatan dakwah dan pembinaan tahfidz atau penghapalan al-Qur'an.

Suatu kekhasan tersendiri bagi PNJ Lauwo dan juga beberapa pesantren yang lahir dari Pesantren As'adiyah Wajo yaitu para santri sering diundang oleh warga untuk menjadi pelaksana acara-acara di rumah warga. Hal ini memberikan beberapa dampak: pertama, pesantren melayani masyarakat secara langsung. Kedua, santri memiliki kesempatan berlatih untuk tampil di tengah masyarakat. Ketiga, menjadi media sosialisasi pesantren kepada masyarakat. Keempat, santri mengetahui secara langsung tradisi yang berkembang di masyarakat.

Sumber daya Manusia (SDM) yang ada di lingkungan pesantren cukup memadai mulai dari Kyai, pengasuh pondok, Guru yang mengajar tapi tidak tinggal di Pondok, Pegawai Pondok, dan santri. Peran lain yang dilaksanakan PNJ Lauwo di bidang keagamaan digambarkan para informan dalam uraian berikut ini:

“...Pesantren Lauwo memperkenalkan agama ke masyarakat setempat. Upaya ini dilakukan melaui berbagi metode seperti majelis taklim, pengajian umum, ceramaha tarawih, khutbah jumat, khutbah hari raya, perayaan hari besar Islam dan kegiatan lainnya. PNJ Lauwo memberikan pembelajaran tentang al-Qur'an. Pembelajaran al-Qur'an adalah pondasi dalam pembelajaran agama. " (P4).

\footnotetext{
13 Hanun Asrohah, "THE DYNAMICS OF PESANTREN: Responses toward Modernity and Mechanism in Organizing Transformation," JOURNAL OF INDONESIAN ISLAM 5, no. 1 (Juni 2011): 66, https://doi.org/10.15642/JIIS.2011.5.1.66-90.
} 
“...Para santri aktif mengikuti program Pemeritah yaitu MTQ dan STQ mulai tingkat Kecamatan, Kabupaten, Provinsi hingga tingkat nasional. Salahsatu kelebihan Lauwo ada para hafidz sehingga mereka menjadi langganan para kepala KUA dalam setiap kegiatan keagamaan. PNJ Lauwo juga aktif mengirim tim safari ramadan yang bertugas memberi ceamah tarawih dan terkadang merangkap menjadi imam tarawih pada berbagai berbagai mesjid."(P5)

“...pimpinan dan Pengasuh PNJ Lauwo terlibat dalam berbagai organisasi masyarakat seperti Majelis Ulama Indonesia (MUI), Badan Kontak Majelis Taklim (BKMT) , Pengurus Hari Besar Islam (PHBI), Badan Komunikasi Pemuda Remaja Mesjdi Indonesia (BKPRMI), Nahdatul Ulama (NU). Hal ini menyebabkan keterlibatan PNJ lauwo dalam kegiatan keagamaan cukup signifikan, baik di tingkat Kecamatan maupun tingkat Kabupaten." (P6).

Keaktifan warga PNJ Lauwo dalam berbagai kegiatan didukung beberapa aspek: Pertama, ketokohan Kyai (pimpinan pondok) yang kharismatik di tengah masyarakat. Kedua, banyak santri penghafal di dalam binaan PNJ Lauwo. Ketiga, Guru/Pembina terlibat aktif dalam kegiatan dakwah secara terus menerus. Keempat, masyarakat Luwu adalah masyarakat religius sehingga banyak sekali kegiatan yang di dalamnya ada kegiatan dakwah seperti acara pernikahan, akikah, selamatan, peringatan maulid, peringatan isra mikraj, ceramah tarawih hingga takziyah kematian. Kelima, santri diberi pembekalan keterampilan dakwah sehingga mereka berani tampil di tengah masyarakat.

Kegiatan-kegiatan PNJ Lauwo di bidang keagaman juga menjadi media untuk merawat kearifan lokal di masyarakat dengan pencerahan dari sisi agama Islam. Kontribusi ini hanya dilakukan oleh institusi Pesantren karena lembaga ini tidak hanya fokus pada pendidikan dan pengajaran tetapi juga pada pengabdian dan pemberdayaan masyarakat. Dengan posisi seperti ini, maka kehadiran PNJ Lauwo berperan memberikan pencerahan kepada banyak masyarakat tentang kedudukan tradidi lokal dalm perspektif Islam.

Dakwah yang diusung pesantren adalah dakwah yang mengusung nilainilai Islam moderat. Menurut Syamsun Nia'm pesantren harus menjadi media promosi Islam yang humanis dan anti kekerasan. 14 Agar dakwah yang dilakukan pesantren lebih diterima masyarakat, maka metode dan materi

14 Syamsun Ni'am, "Pesantren: the miniature of moderate Islam in Indonesia," Indonesian Journal of Islam and Muslim Societies 5, no. 1 (1 Juni 2015): 111, https://doi.org/10.18326/ijims.v5i1.111-134. 
dakwah perlu dikembangkan sesuai kebutuhan era revolusi industri 4.0 yang dipadukan dengan kearifan lokal.

Pesantren perlu mengubah pola dakwah dari dakwah bil lisan menuju dakwah bil hal. Pesantren harus lebih meningkatkan perannya di bidang sosial keagamaan seperti pemberdayaan ekomomi ekonomi warga. Santri perlu dibekali dengan berbagai keterampilan seperti pertanian, perikanan dan perkebunan di samping keterampilan dakwah. Santri perlu mendapat materi kewirausahaan. ${ }^{15}$ Hal ini sangat sesuai dengan posisi pesantren Nurul Junidiyah santrinya banyak dari keluarga petani dan nelayan.

\section{PENUTUP}

Kesimpulan penelitian menujukkan bahwa PNJ Lauwo yang berada di Kecamatan Burau Kabupaten Luwu Timur Sulawesi Selatan telah melakukan peran sosial yang bervariatif. Peran tersebut antara lain dalam rangka perluasan akses belajar, pembinaan generasi muda, pemberdayaan ekonomi, dan peningkatan pengetahuan agama masyarakat di sekitar Pondok dan secara umum. Peran sosial ini perlu ditingkatkan dengan peningkatan kegiatan ekonomi pesantren, optimalisasi peran Ikatan alumni dan pemberdayaan metode pembelajaran santri.

Penelitian ini juga menunjukkan bahwa PNJ Laowu berperan aktif dalam bidang pembangunan keagamaan yang dilakukan Kyai, pengasuh dan santri. Kontribusi utama PNJ Lauwo adanya pembinaan hafizd (penghafal al-Qur'an) yang kemudian menjadi tokoh agama/imam di berbagai wilayah. Kontribusi lainnya adalah dakwah yang dikembangkan PNJ Lauwo adalah Islam moderat yang mampu memadukan nilai-nilai universal Islam dengan budaya masyarakat. Namun metode dakwah yang ada perlu ditingkah lagi dengan dakwah melalui aksi-aksi sosial (pembinaan anak yatim, pembinaan muallaf) dan pemberdayaan ekonomi.

\section{DAFTAR PUSTAKA}

Alwi, B Marjani. "PONDOK PESANTREN: Ciri Khas, Perkembangan, dan Sistem Pendidikannya." Lentera Pendidikan : Jurnal Ilmu Tarbiyah dan Keguruan 16, no. 2 (2013): 205-19.

Arikunto, S. Prosedur Penelitian: Suatu Pendekatan Praktek. Jakarta: PT. Rineka

\footnotetext{
15 Mohammad Nadzir, “Membangun Pemberdayaan Ekonomi Di Pesantren," Economica: Jurnal Ekonomi Islam 6, no. 1 (2017): 37, https://doi.org/10.21580/eco nomica.2015.6.1.785.
} 
Cipta, 1998.

Asrohah, Hanun. "THE DYNAMICS OF PESANTREN: Responses toward Modernity and Mechanism in Organizing Transformation." JOURNAL OF INDONESIAN ISLAM 5, no. 1 (Juni 2011): 66. https://doi.org/10.15642/JIIS.2011.5.1.66-90.

Diana, Ros. "Pemetaan Kapasitas Pesantren Di Kabupaten Maros Provinsi Sulawesi Selatan.” Al-Qalam 22, no. 1 (2018): 39. https://doi.org/10.31969/alq.v22i1.295.

Idi, Abdullah. Sosiologi Pendidikan Individu, Masyarakat, dan Pendidikan. Diedit oleh Safarina HD. Ed. I. Jakarta: Rajawali Press, 2014.

Jamaluddin, Muhammad. "METAMORFOSIS PESANTREN DI ERA GLOBALISASI." KARSA: Journal of Social and Islamic Culture 20, no. 1 (10 Juli 2012): 127-39. https://doi.org/10.19105/karsa.v20i1.57.

Nadzir, Mohammad. "Membangun Pemberdayaan Ekonomi Di Pesantren." Economica: Jurnal Ekonomi Islam 6, no. 1 (2017): 37. https://doi.org/10.21580/economica.2015.6.1.785.

Ni'am, Syamsun. "Pesantren: the miniature of moderate Islam in Indonesia." Indonesian Journal of Islam and Muslim Societies 5, no. 1 (1 Juni 2015): 111. https://doi.org/10.18326/ijims.v5i1.111-134.

Priatmoko, Sigit. "Memperkuat Eksistensi Pendidikan Islam di Era 4.0." TA"LIM : Jurnal Studi Pendidikan Islam 1, no. 2 (2018): 1-19.

Rahayani, dan Yayan. "RESTRUCTURING AND REDESIGNING THE PESANTREN TOWARD AN EFFECTIVE EDUCATIONAL INSTITUTION." TARBIYA: Journal of Education in Muslim Society 4, no. 2 (2017). https://doi.org/10.15408/TJEMS.V4I2.8009.

Selatan, D I Sulawesi. "Dinamika jaringan intelektual pesantren di sulawesi selatan," n.d., 167-81. 
12 | Muhaemin

Halaman ini sengaja dikosongkan 